\title{
ENRAIZAMENTO E GERMINAÇÃO NA PROPAGAÇÃO DE Pfaffia glomerata (Spreng.) Pedersen (ginseng-brasileiro)
}

\author{
Rooting and germination in propagation of Pfaffia glomerata (Spreng.) Pedersen (ginseng-brasileiro) \\ Silvana de Paula Quintão Scalon ${ }^{1}$, Rosilda Mara Mussury ${ }^{1}$, \\ Geovana Thereza Silva da Rosa², Kácila Caetano Moraes², Homero Scalon Filho ${ }^{3}$
}

\begin{abstract}
RESUMO
Conduziu-se este trabalho, com o objetivo de avaliar a propagação sexuada e assexuada de Pfaffia glomerata (ginseng brasileiro). As sementes foram pré-embebidas por 24 horas em $\mathrm{KNO}_{3} 1 \%$; ácido giberélico 50,100 e $200 \mathrm{mg} \mathrm{L}^{-1}$; emágua e as sementes que não receberam tratamento serviram como testemunha. A semeadura foi em placas de petri sobre duas folhas de papel de filtro e a incubação a $25^{\circ} \mathrm{C}$, sob iluminação constante e na ausência de luz. As estacas com $\pm 15 \mathrm{~cm}$ foram imersas durante 6 horas em IAA 250 e IBA $500 \mathrm{mg} \mathrm{L}^{-1}$, ácido bórico $1 \%$ e em água e plantadas em embalagem plástica, contendo terra+areia (1:1). O primeiro experimento foi conduzido em delineamento inteiramente casualizado em esquema fatorial 2 (níveis de luz) x 6 (tratamento de pré-embebição) em 4 repetições de 20 sementes. O segundo em DIC com 5 tratamentos, 4 repetições de 15 estacas por repetição. As sementes de ginseng brasileiro necessitam de tratamento de pré-embebição para acelerar a germinação, sendo a imersão em $\mathrm{KNO}_{3}$ o método mais eficiente, proporcionando $63 \%$ de germinação. Apresentam fotoblastismo neutro, com germinação média de $45 \%$. As estacas de ginseng brasileiro imersas apenas em água apresentaram $100 \%$ de enraizamento, maior número de brotos $(2,5)$ e maior comprimento de raiz $(8,6 \mathrm{~cm})$. A espécie apresenta potencial para ambos os métodos de propagação.
\end{abstract}

Termos para indexação: Ginseng-brasileiro; giberelina; fotoblastismo, auxina, propagação vegetativa,estaquia.

\begin{abstract}
The objective of this study was to evaluate sexual and asexual propagation of Pfaffia glomerata (Brazilian Ginseng). The seeds were pre-soaked for 24 hours in $\mathrm{KNO}_{3} 1 \%$, gibberellic acid 50, 100, $200 \mathrm{mg} \mathrm{L}^{-1}$, and in water. Untreated seeds served as control. Sowing was accomplished in petri dishes on 2 sheets of filter paper, at $25^{\circ} \mathrm{C}$ incubation, under constant illumination, and in the absence of light. The cuttings with $\pm 1,5 \mathrm{~cm}$ were immersed for 6 hours in IAA 250 and $500 \mathrm{mg} \mathrm{L}^{-1}$, boric acid $1 \%$, and in water. Soon after they were planted in plastic containers with soil + sand (1:1). The first experiment was in factorial design 2 (light levels) x 6 (presoak treatment) in 4 repetitions of 20 seeds per repetition. The second in ERD in 5 treatments, 4 repetitions of 15 cuttings per repetition. Brazilian Ginseng seeds need pre-soak treatment to accelerate germination. We found immersion in $\mathrm{KNO}_{3}$ the most efficient method, providing $63 \%$ germination. They presented neuter photoblastism with an average germination of $45 \%$. The Brazilian Ginseng cuttings immersed in water presented $100 \%$ rooting, a higher number of sprouts $(2,5)$, and greater length $(8,6 \mathrm{~cm})$. The species presents potential for both propagation methods.
\end{abstract}

Index terms: Brazilian Ginseng, gibberelin, photoblastism, auxin, vegetative propagation, cutting.

\section{(Recebido em 28 de dezembro de 2007 e aprovado em 16 de outubro de 2008)}

\section{INTRODUÇÃO}

Na região sul de Mato Grosso do Sul, toda a planta de espécies do gênero Pfaffia Mart. são amplamente utilizadas para fins medicinais (Mussury \& Scalon, 2007), sendo que o sistema subterrâneo foi definido por Mussury (2003), como sendo uma raiz tuberosa com crescimento variante que é a parte da planta mais usadas pela população dessa região para vários fins. Siqueira (1987) e Nishimoto et al. (1990) citam a utilização para o aumento das defesas do organismo contra doenças, no tratamento de envelhecimento precoce, na regeneração das células, na purificação do sangue, na inibição do crescimento de células cancerígenas, na regularização das funções hormonais e sexuais, é afrodisíaca, combate a diabete e o reumatismo, sendo ainda bioenergética.

A propagação da maioria das espécies vegetais ocorre por sementes ou por estacas. Entretanto, vários fatores interferem nesses processos, sendo o controle hormonal, a luz, a idade do tecido ou órgão, a posição do ramo na planta e a possível presença de dormência na semente fatores que podem dificultar a propagação e produção de mudas.

Visando ao aumento da produtividade de espécies medicinais com interesse econômico e diante da crescente

1Biólogas, Doutoras, Professoras da Universidade Federal da Grande Dourados/UFGD- Rodovia Dourados/Itahum, Km12 Cx. P. 533 79804-970 Dourados, MS - mara.mussury@ufgd.edu.br; silvana.scalon@ufgd.edu.br;

${ }^{2}$ Graduanda em Ciências Biológicas Faculdade de Ciências Biológicas e Ambientais/FCBA

${ }^{3}$ Engengeiro Agrônomo, Mestre, Professor da Universidade Estadual de Mato Grosso do Sul (UEMS)-Aquidauana, MS - homero@uems.br 
preocupação pela exploração sustentável, torna-se necessário conhecer as formas de propagação e fatores diretamente relacionados. Assim, várias técnicas têm sido propostas para reduzir o tempo entre a semeadura e a emergência das plântulas. A imersão das sementes em agentes químicos como ácido nítrico, nitrato de potássio e água oxigenada é prática comum, usada para estimular a germinação. Esses agentes químicos podem atuar em vários processos do metabolismo das sementes, como nos processos oxidativos, no ciclo das pentoses e na respiração (Zaidan \& Barbedo, 2004). Associado aos processos de germinação e crescimento, os reguladores vegetais atuam de forma específica no desenvolvimento dos vegetais. As giberelinas participam de diversos processos fisiológicos, inclusive como agentes de quebra da dormência (Koormeef et al., 2002).

A germinação das sementes de algumas espécies, principalmente aquelas não domesticadas, é dependente da luz ou da temperatura, sendo que as exigências para a maioria das sementes de plantas silvestres, são pouco conhecidas. Em muitas espécies, a germinação das sementes é mediada pelo fitocromo e a resposta à luz pode manifestar-se pelo fotoblastismo positivo, enquanto, para outras espécies, a ausência de luz promove a germinação - fotoblastismo negativo, enquanto outras são indiferentes à luminosidade - fotoblastismo neutro (Mayer \& PoljakoffMayber, 1989; Silva et al., 2002).

A propagação vegetativa por estaca é ainda a técnica de maior viabilidade econômica para o estabelecimento de plantios "clonais", pois permite com menor custo, a multiplicação de genótipos selecionados, em curto período de tempo. Hartmann et al. (1990) observaram que a posição do ramo na planta é um fator que influencia no enraizamento e desenvolvimento de estacas. Assim, Lazzarini et al. (2001), testando tipos de estacas de Pfaffia glomerata (Spreng.) Pedersen com e sem folhas, constataram aos oito dias após a instalação do experimento, que tanto as estacas apicais como medianas avaliadas haviam perdido as folhas e não observaram diferença estatística entre os tratamentos.

Testando o efeito do tipo de estaca no desenvolvimento das mudas de $P$. glomerata, aos 6 meses após o transplantio, Nicoloso et al. (1999) observaram que estacas obtidas das porções medianas e basal apresentaram maior diâmetro, maior número e maior altura das brotações que as estacas da porção apical. Os autores observaram que estacas das porções medianas e basais apresentaram maior capacidade de enraizamento das mudas a campo.

Estudos sobre a germinação de sementes de $P$. glomerata foram realizados por Renner et al. (2007) submetendo-as em diferentes temperaturas, concentração de giberelina, com ou sem a presença de luz. Os autores observaram que as sementes de ginseng brasileiro são fotoblásticas neutras, não apresentam dormência e não necessitam a adição de $\mathrm{GA}_{3}\left(\mathrm{GA}_{3} 100 \mathrm{mg} \mathrm{L}^{-1}\right.$; $\mathrm{GA}_{3} 200 \mathrm{mg}$ $\mathrm{L}^{-1}$ ) para germinar. O pré-resfriamento das sementes, com ou sem adição de $\mathrm{GA}_{3}$ reduz sua porcentagem de germinação, porém não interfere no tempo médio de germinação.

Como os dados sobre a estaquia e germinação das sementes da $P$. glomerata nas condições de Mato Grosso do Sul são escassos na literatura consultada, neste trabalho, objetivou-se comparar a propagação sexual, via germinação de sementes e a propagação assexuada, via enraizamento de estacas caulinares de $P$. glomerata e a influência da luz e ácido giberélico na germinação de sementes e de auxina no enraizamento das estacas caulinares.

\section{MATERIAL E MÉTODOS}

As sementes e as estacas de Pfaffia glomerata (Spreng.) Pedersen foram obtidas de plantas matrizes cultivadas no Horto de Plantas Medicinais da UNIGRAN, Dourados, MS. As exsicatas estão depositadas no Herbário da Cidade de Dourados (DDMS) sob número 192.

Os testes de germinação das sementes foram realizados no Laboratório de Sementes e os de enraizamento das estacas na casa-de-vegetação, ambos pertencentes à Universidade Federal da Grande Dourados, MS.

Para a propagação sexuada, as sementes foram retiradas dos capítulos, utilizando a técnica do esfregaço, peneiradas para remoção dos resíduos e separadas com auxílio de lente de aumento. Em seguida, elas foram préembebidas por 24 horas em $\mathrm{KNO}_{3} 1 \%$; ácido giberélico 50 , 100 e $200 \mathrm{mg} \mathrm{L}^{-1}$, água e, as sementes que não receberam nenhum tratamento, serviram como testemunha. A semeadura foi realizada em placas de petri sobre duas folhas de papel de filtro e a incubação realizada em câmara de germinação BOD a $25^{\circ} \mathrm{C}$, sob iluminação constante e na ausência de luz. A ausência de iluminação foi obtida embalando as placas com papel alumínio e as contagens realizadas em câmara escura com auxílio de luz verde.

Foi avaliada a porcentagem de germinação na primeira contagem, realizada aos 7 dias após a semeadura e ao final das avaliações e o índice de velocidade de germinação (IVG) das sementes, segundo Popinigis (1985).

$\mathrm{O}$ experimento foi realizado em delineamento inteiramente casualizado em esquema fatorial 2 (níveis de luz) x 6 (tratamento de pré-embebição) em 4 repetições de 20 sementes. Os dados foram submetidos à análise de 
variância e as médias comparadas pelo teste Tukey a 5\% de probabilidade.

Para a propagação assexuada, foram utilizadas estacas basais com aproximadamente $15 \mathrm{~cm}$, as quais foram imersas durante 6 horas em IAA $250 \mathrm{mg} \mathrm{L}^{-1}$; IBA $500 \mathrm{mg} \mathrm{L}^{-1}$, ácido bórico $1 \%$, água e testemunha (sem tratamento), em seguida, plantadas em embalagem plástica contendo terra + areia na proporção de 1:1 e mantidas em sombrite $50 \%$. Aos 45 dias após o plantio, foram avaliadas a porcentagem de enraizamento, o número de brotos e o tamanho da maior raiz.

O experimento foi realizado em delineamento inteiramente casualizado com 5 tratamentos em 4 repetições de 15 estacas por repetição. Os dados foram submetidos à análise de variância e as médias comparadas pelo teste Tukey a $5 \%$ de probabilidade.

As análises estatísticas foram realizadas empregando o programa computacional SANEST.

\section{RESULTADOS E DISCUSSÃO}

Não foi observada interação significativa entre os tratamentos de luz e pré-embebição para nenhuma das características avaliadas. Observou-se maior porcentagem de germinação e índice de velocidade de germinação quando as sementes foram tratadas com $\mathrm{KNO}_{3}$ com médias que não variaram entre os tratamentos com giberelina $\mathrm{e}$ água, porém significativamente maiores que a testemunha (Tabela 1).

Nas condições do estudo, as sementes de ginseng brasileiro apresentaram germinação em torno de $18 \%$ a $63 \%$. Observa-se na literatura grande variação na porcentagem de germinação de sementes de ginseng brasileiro.

Magalhães et al. (1994) verificaram que sementes de ginseng brasileiro apresentaram germinação entre $50 \%$ e 77\%. Mendes et al. (2004) obtiveram 60\% de germinação de sementes cultivadas em meio líquido (Dyer, 1979); Silva Júnior \& Osaida (2005) obtiveram índices entre 93\% a 95\% de germinação. De acordo com Popinigis (1985), a germinação é um processo complexo, compreendendo diversas fases, as quais são individualmente afetadas pela temperatura.

As sementes apresentaram fotoblastismo neutro, embora na presença de luz, a germinação na primeira contagem e o IVG tenham sido significativamente maiores, sugerindo que a presença de luz estimula reações metabólicas mais rápidas que culminam em maior velocidade de crescimento e desenvolvimento das células do eixo embrionário. Esse fato também foi observado por Renner et al. (2007) em sementes de $P$. glomerata.

Resultados semelhantes quanto ao fotoblastismo neutro foram observados para outras espécies como Bauhinia forficata Link., Dimorphandra mollis Benth. e Andira humilis Mart. Ex Benth. (Perez, 1995), Tabebuia serratifolia (Vahl) Nich; T. chrysotricha (Mart. ex DC.) Standl. e T. roseoalba (Ridl.) Sand (Santos et al., 2005).

As estacas de ginseng brasileiro imersas apenas em água e em ácido bórico apresentaram $100 \%$ de enraizamento e maior número de brotos, com médias que não variaram entre si. Entretanto, o maior tamanho de raiz foi observado nas estacas tratadas apenas com água com média que não variou significativamente das estacas tratadas com auxinas. Os resultados sugerem que as doses de auxina utilizadas podem ter causado inibição do processo de crescimento das raízes. As estacas sem nenhum tratamento (testemunha) apresentaram os piores resultados (Tabela 2 ).

Tabela 1 - Porcentagem de germinação final, porcentagem na primeira contagem e índice de velocidade de germinação (IVG) de sementes de Pfaffia glomerata. Dourados, 2006.

\begin{tabular}{ccccccc}
\hline Tratamentos & Germinação final (\%) & Primeira contagem (\%) & \multicolumn{2}{c}{ IVG } \\
\hline Testemunha & 18 & $\mathrm{c}$ & 8 & $\mathrm{c}$ & 0,01 & $\mathrm{~b}$ \\
$\mathrm{KNO}_{3} 1 \%$ & $63 \mathrm{a}$ & 38 & $\mathrm{a}$ & 1,70 & $\mathrm{a}$ \\
GA 50 $\mathrm{mg.L}^{-1}$ & $57 \quad \mathrm{ab}$ & 17 & $\mathrm{bc}$ & 1,17 & $\mathrm{ab}$ \\
GA 100 mg.L & 53 & $\mathrm{ab}$ & 17 & $\mathrm{bc}$ & 1,17 & $\mathrm{ab}$ \\
GA 200 mg.L & 53 & $\mathrm{ab}$ & 22 & $\mathrm{abc}$ & 2,00 & $\mathrm{a}$ \\
Água & 43 & $\mathrm{ab}$ & 30 & $\mathrm{ab}$ & 1,17 & $\mathrm{ab}$ \\
Com luz & 47 & $\mathrm{a}$ & 33 & $\mathrm{a}$ & 1,89 & $\mathrm{a}$ \\
Sem luz & 43 & $\mathrm{a}$ & 11 & $\mathrm{~b}$ & 0,50 & $\mathrm{~b}$ \\
\hline
\end{tabular}

Médias seguidas de mesma letra, nas colunas, não diferem entre si pelo teste Tukey a 5\% de probabilidade. 
Tabela 2 - Enraizamento, número de brotos e tamanho da maior raiz de estacas de Pfaffia glomerata. Dourados, 2006.

\begin{tabular}{cccc}
\hline Tratamento & Enraizamento (\%) & Número de brotos & Tamanho da maior raiz $(\mathrm{cm})$ \\
\hline Testemunha & $25 \mathrm{c}$ & $0,00 \mathrm{c}$ & $1,00 \mathrm{c}$ \\
\hline Água & $100 \mathrm{a}$ & $2,50 \mathrm{a}$ & $8,60 \mathrm{a}$ \\
\hline Ácido bórico 1\% & $100 \mathrm{a}$ & $2,00 \mathrm{a}$ & $3,00 \mathrm{~b}$ \\
\hline IAA 250 mg L & $50 \mathrm{~b}$ & $1,25 \mathrm{ab}$ & $7,25 \mathrm{ab}$ \\
IBA 500 $\mathrm{mg} \mathrm{L}^{-1}$ & $50 \mathrm{~b}$ & $1,00 \mathrm{~b}$ & $7,00 \mathrm{ab}$ \\
\hline
\end{tabular}

Médias seguidas de mesma letra minúscula na coluna não diferem entre si pelo teste Tukey a 5\% de significância.

Resultados semelhantes foram observados para a porcentagem de enraizamento de estacas de guaco, alecrim e carqueja, quanto aos tratamentos de imersão em água pura que propiciou ótimo enraizamento para Mikania glomerata Sprengel - guaco (91,5\%), Rosmarinus officinalis L. - alecrim $(78,5 \%)$ e Baccharis trimera (Less.) A.P.C. - carqueja (95\%), com valores que não variaram significativamente às de alecrim (64\%) e carqueja (99\%) tratadas com boro (Scalon et al., 2003).

Em diferentes espécies de carqueja (Baccharis), Bona et al. (2001), testando concentrações de IBA de 0 a $6000 \mathrm{mg} \mathrm{L}^{-1}$ em estacas apicais, medianas e basais de comprimento variando de $5 \mathrm{a} 20 \mathrm{~cm}$, observaram que não houve diferença entre os tratamentos com IBA sobre o enraizamento de Baccharis trimera (Less.) A.P.C., porém, a maior concentração $\left(600 \mathrm{mg} \mathrm{L}^{-1}\right)$ proporcionou maior número de raízes por estaca. Entretanto, para $B$. articulata Lam., as maiores taxas de enraizamento $(21,1 \%)$ foram observadas na concentração de $1000 \mathrm{mg} . \mathrm{L}^{-1}$ de IBA.

Para Fachinello et al. (1994), a condição fisiológica da estaca possui grande importância no processo, pois, ao longo do ramo, o conteúdo de carboidratos e de substâncias promotoras e inibidoras do crescimento nos tecidos proporciona variação, sendo que estacas obtidas de diferentes porções do ramo tendem a diferir quanto ao potencial de enraizamento. Vlachov (1988), analisando a capacidade de enraizamento dos três tipos de estacas de Platanus acerifolia Ait. verificou que as estacas basais apresentaram enraizamento significativamente superior.

Os experimentos realizados por Nicoloso \& Erig (2002) mostram que o tipo de segmento nodal é um fator a ser levado em consideração e que influencia marcadamente o crescimento das plântulas de $P$. glomerata cultivadas in vitro. De acordo com o autor, segmentos basais proporcionam a maior taxa de multiplicação e plantas maiores em biomassa, altura, número de raízes e brotações. No presente estudo, observou-se para as estacas basais tratadas com água valores elevados no enraizamento, número de brotos e tamanho da maior raiz.
Considerando o custo/benefício, o emprego de auxinas e giberelinas não deve ser recomendado para a propagação do ginseng brasileiro, entretanto, para otimizar a produção de mudas, a imersão das estacas ou das sementes em água deve ser realizada. Renner et al. (2007) observaram a porcentagem de germinação das sementes de ginseng brasileiro de $94 \%$ quando tratadas com água destilada e concluíram que não há necessidade de adição de $\mathrm{GA}_{3}$ para germinação.

Embora a germinação tenha sido relativamente baixa, ela pode ser considerada uma forma prática de propagação, uma vez que a planta produz grande quantidade de sementes e que podem ser semeadas sem a extração das inflorescências, entretanto deve-se levar em consideração a possibilidade de variabilidade genética nas plantas filhas. Por outro lado, a estaquia requer uma quantidade maior de matrizes para a obtenção das estacas, pois, estas apresentam diferentes capacidades de enraizamento, além de serem mais susceptíveis ao ataque de patógenos em razão do corte provocado na estaca.

Diante dos resultados, constata-se que o extrativismo de espécies de $P$. glomerata poderá ser minimizado pelo processo de domesticação e cultivo dessas espécies, quer por sementes ou por estaquia tornando-as, dessa forma, disponíveis para uma parcela maior da população.

\section{CONCLUSÃO}

Nas condições deste experimento, concluiu-se que tanto a estaquia quanto a germinação são métodos igualmente eficientes para a propagação de ginseng brasileiro e que não se justifica o uso de auxinas e giberelina nas dosagens testadas.

\section{AGRADECIMENTOS}

Ao Prof. Dr. Josafá Carlos de Siqueira da Pontifícia Universidade Católica do Rio de Janeiro pela identificação das espécies, ao CNPq (Conselho Nacional de 
Desenvolvimento Científico e Tecnológico) e à FUNDECTMS (Fundação de apoio ao desenvolvimento do Ensino, Ciência e Tecnologia do Estado de Mato Grosso do Sul) pelo apoio financeiro.

\section{REFERÊNCIAS BIBLIOGRÁFICAS}

BONA, C.M.; BIASI, L.A.; ZANETE, F.; NAKASHIMA, T. Propagação vegetativa de três espécies de carqueja. Horticultura Brasileira, Brasília, v.19, n.2, 2001. Suplemento. CD-ROM.

DYER, A.F. The culture of fern gametophyles for experimental investigation. In: __ . The experimental biology of ferns. London: Academic, 1979. p.253-305.

FACHINELLO, J.C.; HOFFMANN, A.; NACHTIGAL, J.C.; KERSTEN, E.; FORTES, G.R. L. de. Propagação de plantas frutíferas de clima temperado. Pelotas: UFPEL, 1994. 179p.

HARTMANN, H.T.; KESTER, D.E.; DAVIS JUNIOR, F.T. Plant propagation: principles and practices. 5.ed. New York: Engliwood Clipps; Prentice-Hall, 1990. 647p.

KOORNNEEF, M.; BENTRINCK, L.; HILORST, H. Seed dormancy and germination. Current Opinion Implant Biology, London, v.5, p.33-36, 2002.

LAZZARINI, G.; LUZ, J.M.Q.; MOTA, J.S.; VASCONCELLOS, M.C. Avaliação de tipos de estacas do caule para propagação da fáfia (Pfaffia glomerata). Horticultura Brasileira, Brasilia, v.19, jul. 2001. Suplemento. CD-ROM.

MAGALHÃES, P.M.; FIGUEIRA, G.M.; PEREIRA, B.; RODRIGUES, J.A. Propagação de algumas espécies do ginseng do Brasil. In: SIMPÓSIO DE PLANTAS MEDICINAIS DO BRASIL, 13., 1994, Fortaleza. Anais... Fortaleza: UFCE, 1994. p.110.

MAYER, A.M.; POLJAKOFF-MAYBER, A. The germination of seeds. Oxford: Pergamon, 1989. 270p.

MENDES, J.; LOPES, J.C.; RENNER, G.D.R. Análise comparativa dos meios MS e de Dyer na germinação de Pfaffia glomerata e Lippia alba. Caderno de iniciação à Pesquisa da Univille, Joinville, v.6, p.153-156, 2004.
MUSSURY, R.M. Caracterização morfo-anatômica dos órgãos vegetativos de Pfaffia glomerata (Spreng.) Pedersen - Amaranthaceae. 2003. 77p. Tese (Doutorado em Ciências Biológicas)-Universidade Estadual de São Paulo, Botucatu, 2003.

MUSSURY, R.M.; SCALON, S.P.Q. Considerações sobre a morfo-anatomia dos órgãos vegetativos de Amaranthaceae com ênfase no gênero Pfaffia Mart.

Revista Brasileira de plantas medicinais, Botucatu, v.9, n.4, p.97-102, 2007.

NICOLOSO, F.T.; ERIG, A.C. Efeito do tipo de segmento nodal e tamanho do recipiente no crescimento de plantas de Pfaffia glomerata in vitro. Ciência e Agrotecnologia, Lavras, p.1499-1506, 2002. Edição especial.

NICOLOSO, F.T.; FORTUNATO, R.P.; FOGAÇA, M.A. de F. Influência da posição da estaca no ramo sobre o enraizamento de Pfaffia glomerata (Spreng.)Pedersen em dois substratos. Ciência Rural, Santa Maria, v.29, n.2, p.277-283, 1999.

NISHIMOTO, N.; SHIOBARA, Y.; INOVE, S.; TAKEMOTO, T.; AKISUE, G.; OLIVEIRA, F.; AKISUE, M.K.; HASIMOTO, G. Ecdisteroides de Pfaffia glomerata. In: SIMPOSIO DE PLANTAS MEDICINAIS DO BRASIL, 11., 1990, João Pessoa. Resumos... João Pessoa: UFPB, 1990.

PEREZ, S.C.J.G.A. Ecofisiologia de sementes florestais. ABRATES, Londrina, v.5, p.13-30, 1995.

POPINIGIS, F. Fisiologia da semente. Brasília: AGIPLAN, 1985.

RENNER, G.D.R.; CAMACHO, F.; PEIXE, S. Ação da temperatura, ácido giberélico e luz na germinação de sementes de fáfia - Pfaffia glomerata (Spreng.)

Pedersen. Semina: Ciências Agrárias, Londrina, v.28, n.3, p.349-354, jul./set. 2007.

SANTOS, D.L.; SUGAHARA, V.Y.; TAKAKI, M. Efeitos da luz e da temperatura na germinação de sementes de Tabebuia serratifolia (Vahl) Nich, Tabebuia chrysotricha(Mart. Ex DC.) Standl. e Tabebuia roseoalba (Ridl) Sand - Bignoniaceae. Ciência Florestal, Santa Maria, v.15, n.1, p.87-92, 2005. 
SCALON, S.P.Q.; RAMOS, M.B.M.; VIEIRA, M. do C. Auxinas e boro no comprimento da maior raiz e número de estacas enraizadas de guaco (Mikania glomerata Sprengl), alecrim (Rosmarinus officinalis L.) e carqueja (Baccharis trimera Less A.P.D.C.) em duas épocas de plantio. Revista Brasileira de plantas medicinais, Botucatu, v.5, n.2, p.71-76, 2003.

SILVA JÚNIOR, A.; OSAIDA, C.C. Ginseng-brasileiro: novo estímulo para o campo e para o corpo.

Agropecuária Catarinense, Florianópolis, v.18, n.2, p.4144, 2005.

SILVA, L.M.M.; RODRIGUES, T.J.D.; AGUIAR, E.B.

Efeito da luz e a temperatura na germinação de sementes de aroeira (Myracrodruon urundeuva). Revista Árvore, Viçosa, v.26, p.691-697, 2002.

SIQUEIRA, J.C. Importância alimentícia e medicinal das Amarantáceas do Brasil. Acta Biologica Leopoldensia, São Leopoldo, v.9, n.1, p.99-110, 1987.

VLACHOV, D.D. Vegetative propagation of sp. Platanus L. through rooting of cuttings. Acta Horticulture, Wageningen, v.226, p.375-378, 1988.

ZAIDAN, L.B.P.; BARBEDO, C.J. Quebra de dormëncia em sementes. In: FERREIRA, A.G.; BORGHETTI, A. (Orgs.). Germinação: do básico ao aplicado. São Paulo: Artmed, 2004. 